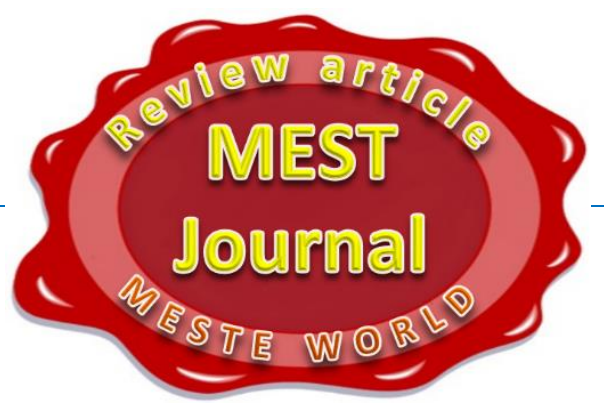

\title{
USE OF OPEN SOURCES OF INFORMATION IN THE INTERESTS OF INTELLIGENCE AND ENSURING INFORMATION SECURITY
}

\section{Olena Ivanenko}

Taras Shevchenko National University of Kyiv, Kyiv, Ukraine

CMESTE

JEL Category: F52

\begin{abstract}
The study of the experience of using open sources of information in the interests of intelligence-byintelligence services studied the methodology and organization of the use of open sources of information in the interests of intelligence and information security of the country. Methods of collecting, analyzing, and processing information are considered, sources for information use are clarified. Information security is an integral part of national security and is closely linked to open-source intelligence. Nowadays, this type of intelligence is relevant because sometimes the ability to obtain intelligence through closed sources is significantly limited. The information obtained in this way should be carefully checked and analyzed, compared with the information obtained through intelligence and vice versa. The considered advantages of open sources of information are that the risk of failure of the agent is excluded or considerable means and efforts for the search of such are saved. The information provided by the World Wide Web is truly inexhaustible. In total, more than two-thirds of the intelligence obtained is obtained through open sources of information. The studied methods of working with information obtained from open sources have shown that analytical intelligence is a component of intelligence activities, which consists of identifying, evaluating, forecasting various political, economic, and social processes, events, activities based on information, mostly obtained from open sources, extracted by an exploration of other types (agency, technical).
\end{abstract}

Keywords: open sources of information, World Wide Web, information security of the country, analytical intelligence.

\section{INTRODUCTION}

Actuality. It consists of concentrating the efforts of the country's foreign intelligence service on priority areas of activity, ensuring the adequacy of measures to counteract existing and potential risks and threats to the country's national security,

The address of the corresponding author: Olena Ivanenko

莑e_ivanenko@ukr.net focusing on performance only and the result. The use of open sources of information in the interests of intelligence is one of the most important components of ensuring the national security of any country in the world. The vital activity of the entire state mechanism and often the existence of the state as such depends on how intelligence works. According to various experts, from 80 to $90 \%$ of the information needed for decisionmaking can be obtained from open sources and only $10 \%$ from closed sources. 
The goal of this research is to study the experience of using open sources of information in the interests of intelligence by foreign intelligence services and the application of their experience by the country's foreign intelligence service.

Research methods and ways to use open sources of information on the example of foreign experience include:

- analysis of the American experience of using open sources of information.

- research of the experience of using open sources of information by European secret services.

- study of the organization of collection and analysis of information based on OSINT.

\section{THE ROLE AND IMPORTANCE OF ANALYTICAL INTELLIGENCE THROUGH THE INTERNET}

One of the most promising areas of work of the security service of a certain state entity to ensure national security is analytical intelligence (search) using the Internet. Many experts also call this set of measures of computer intelligence. Its essence is to search for and transmit information from computer systems and networks of the "World Wide Web" with its subsequent verification and analytical processing.

Both state and non-state special services are showing great interest in analytical methods. This is because the Internet contains huge amounts of information that are of operational interest to both the former and the latter.

Therefore, in many countries around the world, including law enforcement agencies in Russia (MIA and FSB), the United States (FBI), and Germany (BKA), special units of analytical intelligence have been created via the Internet.

The sphere of activity of these state structures is legal intelligence in the global network, organization of communication channels with the agency, collection of materials on operationally significant situations, active activities in the network, the study of personal characteristics of politicians, scientists, military, and collection and analysis of information. is of interest from the point of view of state security. Similar units operate in transnational corporations, which are increasingly becoming states within states.
Also, there are independent research centers that specialize in finding the right data in the "digital ocean" of information. In Western Europe and the United States, gathering information through the Internet has long been a lucrative business. According to the open press, in France alone there are now more than a dozen companies whose task is to study documents, including tables and figures that exist on the Internet. An example is the linguistic engineering company MAAG, which focuses on information and analytical support for such key sectors of the French economy as the aerospace industry, transport, and energy.

Special "data collection processors" are used for global research on the Internet. In this particular context, the term "processor" has nothing to do with a microprocessor, it is part of a program that defines how the program itself manages and manipulates data. The data collection processor uses software called "robot": "robot" obtains the necessary information using a whole arsenal of linguistic, semantic, and statistical analysis. Acting autonomously, data collection processors intercept any requested information as soon as it appears on the Internet. The first to be declassified was the French processor Taiga (Traitement automatique d'information geopolitique d'actualite - "automatic processing of current geopolitical information"). This software package was initially developed for the needs of French intelligence, where it then worked fruitfully for 11 years, after which it was transferred for commercial use. The tasks now set for him by civilian experts have remained the same, namely monitoring the Internet to extract valuable information from patent databases, news agency reports, and scientific conference publications.

The method of conducting analytical intelligence using this software is as follows: processing open access materials available on the Internet, the program of statistical analysis is the so-called maps of work in various fields of science. In turn, this allows analysts to identify the most promising research in industries where competition is still relatively small. The results of quantitative and qualitative analysis of the results of scientific laboratories make it possible to assess the degree of the creative atmosphere of research teams. It can also be quite useful in identifying "promising fliers", ie researchers who in a relatively short time can change some research centers of interest, 
and thus who are familiar with the results of these research centers.

It is worth mentioning another French development. To conduct a semantic analysis of large information arrays, Acetic, together with scientists from the University of Paris, has developed a package of Tropes applications. The necessary information is selected according to keywords and concepts that are related in meaning. For example, the name of the aircraft "Mirage" is associated with the words "airplane", "fighter", and the set of words "US Secretary of State" is automatically associated with the words "minister", "politician". This software allows one to simultaneously analyze two text pieces of information with a volume of several dozen book volumes. Also, "Tropes" allows one to create the necessary information scenarios, based on which is automatically not only the search but also the target grouping of the necessary data.

Technological progress does not stand still in the city, and therefore it is obvious that if the state intelligence services provide such developments for commercial use, it can only mean that they have received something much more powerful.

Noemic, which replaced Taiga at the battlefield, not only scans but also automatically "combines sources", processing the received information at a rate of 1 billion characters per second, regardless of whether it exists as a ready-made database or, for example, transmitted by an open news agency in any language in the form of a complete text. This semantic data processor is also capable of processing concepts, metaphors, and a set of ideas that deserve its attention. If, for example, they are tasked with identifying all the links between Hong Kong and American microelectronics companies in the last five years, it will only take a few hours.

The American analog of these software packages, called "Topic", was also developed from the beginning for intelligence purposes. This system was born as a result of long-term research carried out under the control of the CIA. Today, it is also transferred to commercial use and all rights to it belong to the California firm "Verity", the world leader in documentary data collection.

Verity and its competitors are not far behind. For example, the American company "Intelligent
Search Solutions" has launched a software package "InfoTracer", which is designed to collect economic intelligence on the Internet. To filter the information, the specified software uses keywords and phrases, after which messages of the necessary content for users are automatically composed. They may contain, for example, data on the business operations of a particular company and its partners, the technologies they use and manufactured products, as well as the names of management.

In this regard, I would like to note that the emergence of new information technologies has almost equalized the ability of competitors to obtain the necessary source information. Now the key is search speed and proper analysis. This is exactly what data collection processors will help, which allows one to "extract" and analyze the necessary information from large arrays of information. Professionals are well aware that economic intelligence can be conducted without computer hacking, simply by processing a huge algorithm of huge amounts of information available to every Internet user. According to experts, today in the United States alone there are about 150 companies that specialize in the analysis of data obtained from the Internet. And new companies appear like mushrooms after the rain.

But at the same time, it should be noted that analytical intelligence utilizing the Internet is a stick at two ends. The fact is that if one track and analyze the subject of data of interest to a particular entity available on the Internet, it is quite easy to build a causal relationship and identify long-term intentions of the company, the level of its encroachments, which in turn it will be possible to assess the level of its development. For this purpose, special "robots" have been developed, which intercept data on the operation of the system, which is engaged in a purposeful collection of information.

The most advanced corporations actively use disinformation technologies to mislead about their business contacts, developments, financial, and marketing plans. With the participation of industry experts and with the help of special software packages, which also operate on the principles of linguistic and statistical analysis, from pieces of already published texts and some complex terms 
are created and published on the Internet various materials that frankly do not correspond to the true state of affairs: "industry reviews", "scientific" articles, and sometimes entire databases and data banks.

The effectiveness of disinformation measures is assessed by ordering analytical reports for oneself through fictitious companies from network intelligence providers. In the future, the controlled leak of these reports to the press acts as a "circle on the water" and is the material of "secondary consolidation" of the necessary stereotypes in the objects of disinformation attack.

Previous material has been able to convince most readers that the use of analytical techniques opens ample opportunities to quickly obtain the necessary data from both professional databases and data banks, and unstructured information available on the Internet.

These circumstances naturally allocate analytical intelligence to the independent direction of business units, and in combination with other technologies of analytical information processing, which will be described below, allow us to talk about a range of intelligence activities based on modern information technology.

In this section of scientific work, we will focus on the information retrieval component of analytical intelligence, as in the method we are researching, searching the Internet is only a preliminary search for information.

About $10-15 \%$ of the necessary information is available on the Internet already in the finished form (only verification is required), and the other $85-90 \%$ are obtained as a result of the comparison, analysis, and synthesis of disparate and scattered from different sources of facts, which can be a fully fragmented image of reality. Naturally, the information obtained in this way needs clarification and verification.

First, the efficiency of providing information to some extent compensates for its incompleteness. Secondly, as a rule, at the initial stage of acquaintance and this volume satisfies the customer. Third, if there is further interest in the subject, this preliminary information will help the customer to place emphasis and set guidelines for further work. The advantage of this type of intelligence is to minimize labor, moral, and financial costs.

The following examples are successful examples of the use of the Internet in competitive intelligence. The security service of one of the enterprises, collecting information about the alleged partner in one of the remote subjects of the Russian Federation via the Internet, went to the official website of this subject of the Federation. The official press represented there, painted a possible partner, without sparing creative forces and budget funds. But the analysts went further and through a link on the official website of the administration we got the website of the Chamber of Commerce and Industry, and from there to the website dedicated to local media. This site published materials of one of the newspapers in opposition to the head of the region's administration and thus significantly expanded their knowledge about the object under study in terms of the "negative" available to it.

It is worth noting that with the right approach, even the official websites of businesses, businessmen, politicians, and public figures will be able to report a lot of interesting information.

For example, on the eve of a major industry fair, one of the largest Western companies on the website of its main competitor noticed information about a massive company to stimulate its product. This allowed to timely revise the price list prepared for the exhibition and deprive the competitor of the opportunity to play on a clear price advantage.

For example, other information may appear. For example, a competitor's announcement about finding a specialist in a new field has appeared on the Internet, so this can be a signal to us about a change in the priorities of the competitor's business. Similarly, if one need information on potential foreign partners, then with the appropriate approach and knowledge of a foreign language, this is also not a problem. On Western servers, there are a lot of available sites with interesting information. It is important to know where, how, and what to look for.

In the same way, information with evidence of participation in separatist riots in eastern and southern Ukraine appeared on the Internet many times, allegedly on behalf of Ukrainian citizens, citizens of the Russian Federation. The issue of 
the information war against Ukraine and the nature of threats will be discussed in more detail in the next section.

In early 2005, the ZabaSearch service was launched online for public testing, which is one of the most complete and comprehensive information search servers for people living in the United States.

ZabaSearch has an advantage over conventional free search engines such as Yahoo People Search, whose functionality is limited to information from phone directories.

The ZabaSearch database contains all unpublished phone numbers, personal information for the last ten years, and satellite photos of the apartment. ZabaSearch builds its index databases by processing thousands of sources on the Internet. Currently, the index of this system contains more than 2 billion records - an average of $10-12$ records per US citizen.

With a free search query, if one correctly identifies the name and residence of the wanted person, he/she can get the name, date of birth, and home phone number of any American. If pays $\$ 25$, one will be provided with a complete dossier, which will include information about the person involved in the police, his tax debts, and bankruptcies. The trade-in personal information in the United States is a multibillion-dollar market operated by a variety of organizations, including banks and government agencies. Thus, all customer information is sold by the US Postal Service.

The main disadvantage of "free" information is the lack of guaranteed completeness and reliability of data, as well as the significant time required to find the necessary information. Often the data presented on the sites are not updated at all or are updated very irregularly.

Information obtained from open sources can be of great value in the decision-making process. It is important to use different sources of open information and take into account the degree of objectivity of each source. Based on an array of information obtained from several sources, a vision of the situation is created. It will not be superfluous to use various analytical reviews and blogs on the Internet, as they may also contain valuable information. Such blogs are run by various politicians and public figures, journalists, political scientists, experts, etc.

In the conditions of growing interrelations and interdependence of the states at the preservation of many global dangers and threats, national security becomes a component of the general world safety, efforts of all people in the preservation of the world, democracy, humanization of modern relations. Information is the basis for decision-making in the field of public policy and national security. It is no secret that the information space is also used for information warfare.

Open sources of information are not only a channel for obtaining information but also a source of various threats to the country's national security.

\subsection{Information security as an integral part of national security}

The information security of the country is an organic component of the national, so its consideration is necessary for the formation of basic knowledge and ideas about national security.

Given this, we can state a new understanding of information security issues. Thus, B. Kormych interprets information security as a state of protection of the norms and parameters of information processes and relations established by law, which provides the necessary conditions for the existence of the state, man, and society as subjects of these processes and relations.

Some scholars consider information security as a state of protection of vital interests of the individual, society, and the state, which minimizes damage due to incompleteness, lateness, inaccuracy of information, or negative information impact, due to the negative consequences of information technology, as well as unauthorized dissemination information.

Information security of society is also defined as the impossibility of harming its spiritual sphere, cultural values, social regulators of human behavior, information infrastructure, and messages transmitted through it.

The development and implementation of almost all areas of information technology significantly change the structure of society, as well as 
transforms international relations. One of the most important directions of this transformation is the realization of national interests in ensuring national security.

Since the middle of the twentieth century, the rapid development of information technology, which has acquired a global character. The global information industry in the early ' 90 s of the last century reached 2 trillion. US dollars, and at the beginning of the XXI century increased by an order of magnitude. Based on this, we can say that the world is rapidly forming an information society. Its main feature is that the strategic resource is information that can interact not only with the material but also with the spiritual world of man.

Thus, we consider the problem of information security in the context of the formation of the information society.

The urgency of this issue is due to many factors:

- now the main strategic national resource, the basis of economic and defense power of the state is information and information technology.

- information in the modern world is an attribute on which the efficiency of modern society depends.

- information technology has fundamentally changed the volume and importance of information that circulates in the technical means of its storage, processing, and transmission.

- general computerization of the main areas of activity has led to a wide range of internal and external threats, non-traditional channels of information loss, and unauthorized access to it.

- mass equipping of state institutions, enterprises, organizations, and individuals with computer equipment and their inclusion in the world information spaces involves a real threat of creating extensive systems of regular unauthorized control over information processes and resources, deliberate interference in them.

- the reality of today has become the use of information weapons and information wars.

- the imperfection of legal regulation of public relations.

In the field of information, security leads to serious negative consequences that make it difficult to maintain the necessary balance of interests of the individual, society, and the state, the formation of competitive local news agencies and media:

- unfair use of information space within the state leads to a decrease in the level of internal information security of Ukraine, the direct consequence of which is the destabilization of the socio-political situation, actions of resistance to the adoption of certain state decisions.

- constitutional rights of citizens to privacy, personal and family secrets, correspondence do not have sufficient organizational, legal, and technical support.

- the situation with ensuring the preservation of state secrets is deteriorating, mechanisms for ensuring official and commercial secrets are insufficiently developed.

- significant damage is caused to the personnel potential of the teams of those enterprises that operate in the field of information technology.

- lag of domestic information technologies forces the creation of information systems to purchase imported equipment and attract foreign firms, which increases the likelihood of unauthorized access to processed information, increasing dependence on foreign manufacturers of computer and telecommunications equipment, software.

As a result, the process of informatization of society is developing rapidly and partly unpredictable.

\section{CLASSIFICATION AND DESCRIPTION OF OPEN SOURCES OF INFORMATION}

Given the rapid technological development of the information society and new communication opportunities, the number of potentially possible both open and relatively open and closed electronic sources of information has recently expanded significantly.

The modern world of information technologies and the comprehensive informatization of society integrate every citizen into the network, whether he wants to or not. The database of any enterprise or organization is contained on electronic media, which are transmitted to government agencies and institutions for accounting or control. 
There are many types of sources of information. Open sources of information include print media, television and radio, the Internet, various professional and analytical publications, and more.

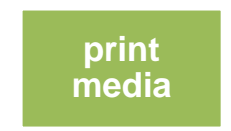

television and radio the Internet professional

publications

analytical

reviews

Figure 1 Open sources of information (adapted by authors)

One of the most promising areas is analytical intelligence through the Internet. This set of measures is referred to by many experts as computer intelligence. Its essence is to find and transmit information from computer systems and networks of the "World Wide Web", followed by verification and analytical processing.

Both state and non-state special services are showing great interest in analytical intelligence methods. This is because the Internet contains large amounts of information that may be of operational interest to both the former and the latter. Of course, information about a person has previously been subject to accounting in various bodies or institutions.

From the end of the twentieth century until today, new developments in the field of computer technology allow us to bring to a qualitatively new level the work of processing data contained in a computer network. Modern systems based on the analysis of the obtained data can predict actions or events. After all, modern information systems can form an information file on the requested object with data that were not only entered by the subject of the application (government agency or organization) but also by other subjects knowingly or even accidentally. It is possible to obtain personal information from sources such as the Internet, including financial history and video surveillance.

Analysis of social networks is recommended by banks when deciding on a loan. The practice of human resources departments of many private organizations to check a candidate by analyzing his profile on social networks is widespread. After all, at the meeting, the candidate will show himself as the best side, often hiding the negative aspects of his personality. Whereas social networks contain information over a long time and can show different aspects of the personality, from friends on the network to tags (likes) of specific news, photos or videos, and so on.

Analytical intelligence is the study and systematization of information that can be obtained both within the method itself and using other methods of ORD (visual observation, reconnaissance surveys, operational installations, electronic control).

Recently, specialized computer intelligence programs have been used to conduct computer intelligence. Due to their specific functions, intelligence programs, in comparison with other search and analytical programs, allow to expand the search area, reduce the search term, identify latent connections, increase the value of the received information. Intelligence computer programs are the most versatile and therefore the most widely used analytical intelligence tool. S. Ovchinsky emphasizes the extremely important role of modern methods of processing a variety of information for the formation of analytical intelligence as an "independent activity".

Computer intelligence is an activity that involves finding and retrieving real-time information from computer systems and networks. The need for this event is due to the peculiarities of modern crime. According to $\mathrm{O}$. Demyanchuk, computer networks, first, the Internet, are increasingly used by criminals to create illegal markets for weapons, drugs, human organs, pornographic products, explosive devices, offers to provide killer "services", as well as a way to disseminate information on the manufacture of improvised explosive devices, the propaganda of national hatred and calls for war. 
It should be noted that open sources should include not only those to which public access is possible but also those to which access is technically possible due to, for example, unprofessionalism or negligence of the information protection service or system administrator. There are leaks of valuable and confidential information in the public domain. Such a leak may be aimed at deliberate misinformation or may contain reliable information, as the perpetrators may be prosecuting their property.

\section{CONCLUSIONS}

The result of counteracting external threats to the national security of the state is intelligence activities to participate in the fight against terrorism, international organized crime, drug trafficking, illegal trade in weapons and their technology, illegal migration.
Monitoring of special information operations of macro- and micro-level planned to achieve a certain goal allows to counteract external threats to the national security of the state and to carry out systemic measures, namely:

- prevention of several real terrorist acts against Ukrainian diplomatic missions abroad.

- assisting in the evacuation of several thousand citizens from conflict zones and increased terrorist activity Palestinian-Israeli, Georgian-Ossetian, from Iraq, Syria, Lebanon, Libya, and other countries.

- in cooperation with the state authorities of the country and foreign partners to implement measures to assist ship-owners in the release from piracy of several ships and their crews, etc.

\section{WORKS CITED}

Akimova, G., Bogdanov, D., Musatov, I., Pashkin, M., Soldatov, D., \& Somin, N. (2013) Modern automated technologies for processing heterogeneous information.

Analytical processing of heterogeneous textual information. [Electronic resource] .- access mode: http://www.bytemag.ru/articles/detail.php?ID=8965\&sphrase_id=3447289

Baranov, A. (2001) Information sovereignty or information security? National Security and Defense, (1), 72-75.

Diaghilev, A., Kiselev, S., \& Somin, N. (1998) Statistical model of text rubrication on the example of media reports. Distance education, (7), 16-21.

How to find information. Collection of information from open sources. Network espionage or information gathering? [electronic resource].- access mode: http://www.vsepoisk.ru/2009/03/blog-post_27.html

Information security of Ukraine: problems and ways to solve them. National Security and Defense, (1), 60 - 69.

Kormich, B. (2004) Organizational and legal bases of information security policy of Ukraine. Author's ref. dis. for science. 15-20.

Kharlamov, A. (2002) Automatic structural analysis of texts. Open Systems, (10).

Magazine "IT - sector". Internet intelligence. [electronic resource].- access mode: http://it-sektor.ru/razvedkasredstvami-internet.html

Yushchuk, E., \& Nezhdanov, I. (2020) Competitive intelligence. Techniques of information analysis in competitive intelligence. [Electronic resource].- access mode: http://ci-razvedka.ru/Analiz-informatsii.html

Received for publication:

Revision received:

Accepted for publication:
06.09.2020

23.09.2020

30.12 .2020 


\section{How to cite this article?}

Style - APA Sixth Edition:

Ivanenko, O. (2021, January 15). Use of open sources of information in the interests of intelligence and ensuring information security. (Z. Cekerevac, Ed.) MEST Journal, 9(1), 37-45. doi:10.12709/mest.09.09.01.05

\section{Style - Chicago Sixteenth Edition:}

Ivanenko, Olena. 2021. "Use of open sources of information in the interests of intelligence and ensuring information security." Edited by Zoran Cekerevac. MEST Journal (MESTE) 9 (1): 37-45. doi:10.12709/mest.09.09.01.05.

Style - GOST Name Sort:

Ivanenko Olena Use of open sources of information in the interests of intelligence and ensuring information security [Journal] // MEST Journal / ed. Cekerevac Zoran. - Belgrade - Toronto : MESTE, January 15, 2021. - 1 : Vol. 9. - pp. 37-45.

Style - Harvard Anglia:

Ivanenko, O., 2021. Use of open sources of information in the interests of intelligence and ensuring information security. MEST Journal, 15 January, 9(1), pp. 37-45.

Style - ISO 690 Numerical Reference:

Use of open sources of information in the interests of intelligence and ensuring information security. Ivanenko, Olena. [ed.] Zoran Cekerevac. 1, Belgrade - Toronto : MESTE, January 15, 2021, MEST Journal, Vol. 9, pp. 37-45. 